\title{
Effect of biotin on milk performance of dairy cattle: A meta-analysis ${ }^{1}$
}

\author{
B. Chen, C. Wang, Y. M. Wang, and J. X. Liu ${ }^{2}$ \\ Institute of Dairy Science, College of Animal Science, Zhejiang University, Hangzhou 310029, P. R. China
}

\begin{abstract}
A meta-analysis of the effect of biotin on production outcomes of dairy cattle was conducted following a literature review. A total of 11 studies from 9 papers, with information on the milk production and composition data from a total number of 238 cows were extracted and analyzed using meta-analysis software in Stata. Estimated size of effect of biotin was calculated for dry matter intake (DMI), milk production, and composition. Heterogeneity was not significant for all of the parameters (the highest $\mathrm{I}^{2}=12 \%$ ). Therefore, fixed effects models were used for analysis. With the addition of biotin to lactating dairy cattle, DMI and milk production increased by 0.87 and $1.66 \mathrm{~kg} / \mathrm{d}$. No significant effect on percentage of milk fat and milk protein was observed. Additionally, Begg's test indicated no evidence of substantial publication bias for all variables. The influence analysis shows that the removal of any study did not change the direction or significance of the point estimates. It can be concluded that the use of biotin supplements increases DMI and milk yield in lactating dairy cows.
\end{abstract}

Key words: biotin, dairy cattle, lactation, metaanalysis

\section{INTRODUCTION}

Biotin, a water-soluble B vitamin, is an essential nutrient for both rumen bacteria and the dairy cow. Apart from being indispensable for gluconeogenesis, fatty acid synthesis, and protein synthesis, biotin is also required as a cofactor for the 4 enzymes (acetyl-CoA carboxylase, pyruvate carboxylase, $\beta$-methylcrotonyl-CoA carboxylase, and propionyl-CoA carboxylase) involved in the carbon dioxide fixation reaction (Dakshinamurti and Chauhan, 1988). In addition, most cellulolytic ru-

Received August 27, 2010.

Accepted February 21, 2011.

${ }^{1}$ This study was supported in part by the earmarked fund for Modern Agro-industry Technology Research System (No. nycytx-02-06) and National Key Basic Research Program, Ministry of Science and Technology, P. R. China (Grant No. 2011CB100801).

${ }^{2}$ Corresponding author: liujx@zju.edu.cn men bacteria require biotin for growth (Baldwin and Allison, 1983). Abel et al. (2001) found that biotin can improve fermentation of fiber in the rumen. Moreover, biotin is important as an intracellular cementing substance and for keratinization to improve the hardness of a cow's hooves and horns (Fritsche et al., 1991). Biotin had a positive effect on the structure and quality of new horn for cattle (Lischer et al., 1996).

Biotin from supplements is only partly degraded. It has been reported that biotin was not extensively metabolized in the rumen (NRC, 2001). Schwab and Shaver (2005) found that a significant increase in biotin in milk and plasma, suggesting that biotin supplemented in an unprotected form was not completely degraded or utilized by ruminal microbes. Based on positive efficacy reported for biotin in their studies and the studies of Margerison et al. (2002), Midla et al. (1998), and Zimmerly and Weiss (2001), Majee et al.(2003) suggested that biotin did not require ruminal protection. Because not all biotin is metabolized in its unprotected form, and unprotected biotin was used in these studies, there was probably no need to protect the supplemented biotin.

In some studies (Midla et al., 1998; Bergsten et al.,1999; Zimmerly and Weiss, 2001), addition of biotin at $20 \mathrm{mg} / \mathrm{d}$ increased milk production $(1.0,2.9$, and $2.8 \mathrm{~kg} / \mathrm{d}$, respectively) in lactating cows, whereas Fitzgerald et al. (2000) and Ganjkhanlou et al. (2007) observed that biotin had little effect on milk yields. The difference between these results may be caused by the small number of animals used in one study and the specific conditions of the experiment. A thoroughly systematic and quantitative assessment of published findings is necessary to arrive at a comprehensive conclusion. Meta-analysis is a method that has been used to evaluate treatment effects in human health care (Egger et al., 2001), animal science, and veterinary medicine across many studies (Whitehead, 2002; Duffield et al., 2008; Chen and Liu, 2010). Although many factors may influence results of studies, such as cows, diets, and environments, the result of heterogeneity in metaanalysis can be used to detect the difference between studies. Considering the need for biotin for dairy cattle and nonconformity of the results, an investigation of 
biotin by meta-analysis would be helpful in elucidating its effect on milk production and the inconsistent results across studies.

The objective of this study was to investigate the effect of biotin on lactation performance in dairy cattle using meta-analytic methods.

\section{MATERIALS AND METHODS}

\section{Literature Review}

A literature review was initially conducted by using Web of Science, Ovid, ScienceDirect and Google Scholar search engines to create a data set of biotin papers using the key words biotin and dairy. Studies included in the data file needed to meet all of the following criteria: (1) the populations studied were lactating Holstein dairy cows; (2) the information on production outcomes was detailed enough for analysis of effects of biotin; and (3) the biotin addition level was $0.96 \mathrm{mg} /$ $\mathrm{kg}$ of $\mathrm{DM}$ or $20 \mathrm{mg} / \mathrm{d}$. These levels are widely used for supplementation of biotin in the literature. Other biotin supplementation levels are used in some studies, including $10 \mathrm{mg} / \mathrm{d}$ by Zimmerly and Weiss (2001) and $40 \mathrm{mg} / \mathrm{d}$ by Yang et al. (2009), but not enough studies exist to make a definitive conclusion for different supplementation levels via meta-analysis. Abstract and conference papers were not included owing to the lack of related data. A great deal of literature was found on the effects of biotin on dairy cattle, but most of them were on its effect on hoof quality. Only 12 articles were found on the subject that provided detailed data on milk performance, but 3 of them were excluded because the supplementation levels of biotin did not match the standard used in the meta-analysis. A total of 11 trials containing production data were identified from 9 papers (Table 1 ). The average concentrate ratio in diets in the literature used for the meta-analysis was $45.9 \%$. The average DMI and milk yield were $23.5(\mathrm{SD}=1.0)$ and $34.4(\mathrm{SD}=1.8) \mathrm{kg} / \mathrm{d}$, respectively. Lactation stage covered a wide range, from 0 (Zimmerly and Weiss, 2001) to 267 DIM (Ferreira et al., 2007).

\section{Outcome Evaluated and Data Extraction}

A template for data extraction was drafted to include mean, standard deviation, and number of cows per treatment group. Parameters analyzed included DMI, milk yield, and milk composition (fat and protein). The change in BCS and BW were not analyzed for lack of relevant data. The precision of the estimate was based on the reported standard deviation in papers for the treatment and control groups. If an estimate of standard deviation was not provided, it was calculated by

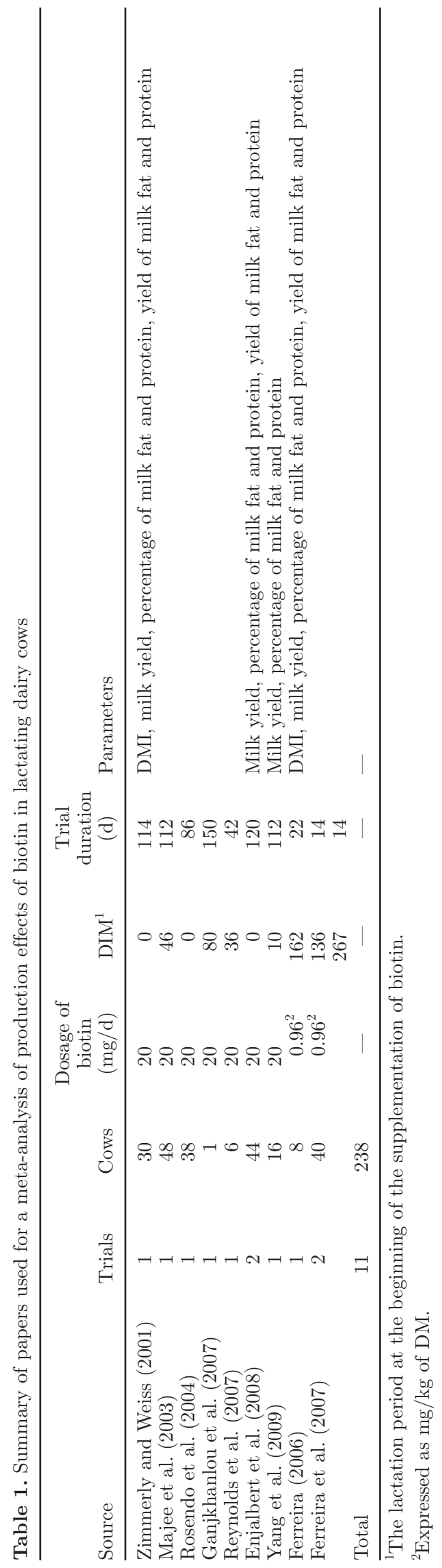


Table 2. Summary of effect size estimates of biotin on production in lactating dairy cows, derived from meta-analysis ${ }^{1}$

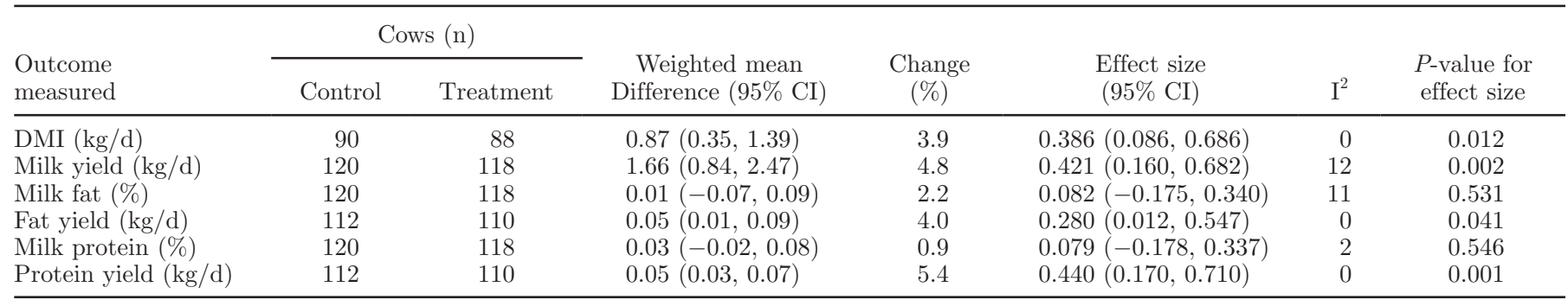

${ }^{1}$ This includes the test of heterogeneity $\left(\mathrm{I}^{2}\right)$.

multiplying the standard error of means by the square root of the number of cows.

\section{Statistical Analysis}

The effect of biotin supplementation on milk performance in lactating cows was evaluated by meta-analysis using the fixed-effects or random effects model to estimate the effect size (ES), 95\% confidence interval, and statistical significance of ES with Stata software (Intercooled Stata V. 10.0; StataCorp LP, College Sta- tion, TX). The ES estimate analysis was conducted using a standardized $\mathrm{z}$ statistic, and all outcomes that weighted mean differences of treatment relative to control were calculated to show the specific values of the effects of biotin on dairy cattle. Statistical significance was considered at $P \leq 0.05$. Failure to account for the heterogeneous errors violates the assumption of identical distribution of residual error (St-Pierre, 2001). The $\mathrm{I}^{2}$ statistic (Higgins et al., 2003) was used to determine degree of heterogeneity, which described the percentage of total variation across studies that was due to hetero-
Source

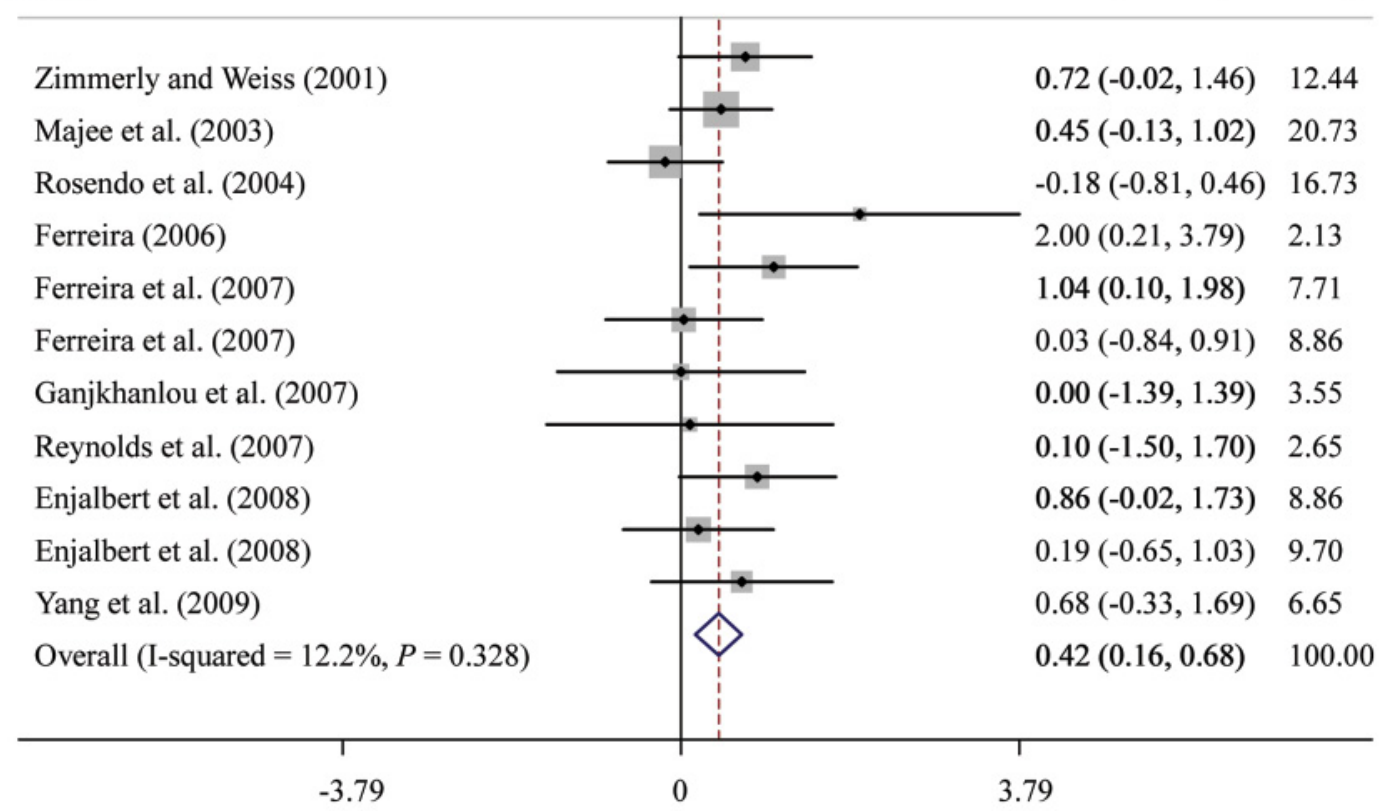

Standardized mean difference

Figure 1. Forest plot of the effect of biotin on milk production in lactating dairy cows. The x-axis shows the standardized mean difference (SMD, standardized using the z-statistic). The length of the horizontal line represents the $95 \%$ CI for the standardized mean difference of biotin on milk production from each study, the size of the square in the center is proportional to the weight assigned to the study, and specific values are listed in the following row. The diamond at the bottom on the right of the solid vertical line represents the positive effect of biotin on milk production. The overall $\mathrm{I}^{2}$ statistic (a test of heterogeneity) indicated that heterogeneity for the effect of biotin on milk production was not significant $(P=0.328)$. Color version available in the online PDF. 
Source

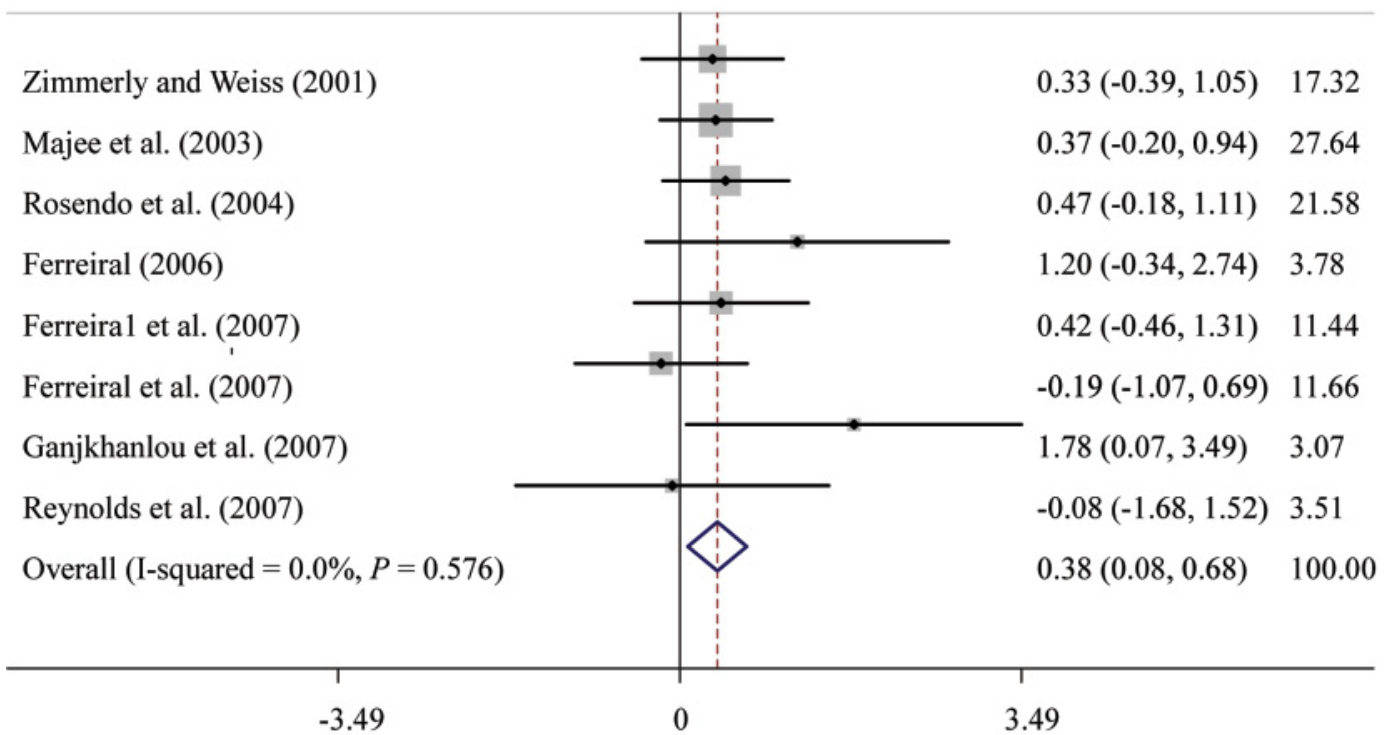

Standardized mean difference

Figure 2. Forest plot of the effect of biotin on DMI in lactating dairy cows. The x-axis shows the standardized mean difference (SMD, standardized using the z-statistic). The length of the horizontal line represents the $95 \%$ CI for the standardized mean difference of biotin on DMI from each study, the size of the square in the center is proportional to the weight assigned to the study, and the specific values are listed in the following row. The diamond at the bottom on the right of the solid vertical line represents the positive effect of biotin on DMI. The overall $\mathrm{I}^{2}$ statistic (a test of heterogeneity) indicated that heterogeneity for the effect of biotin on DMI was not significant $(P=0.575)$. Color version available in the online PDF.

geneity rather than chance (Duffield et al., 2008). The $\mathrm{I}^{2}$ was calculated by the Q statistic (Egger et al., 2001) using the following equations:

$$
\begin{gathered}
Q=\sum w_{i}\left(T_{i}-\bar{T}\right)^{2} \\
I^{2}(\%)=\frac{Q-(K-1)}{Q} \times 100,
\end{gathered}
$$

where $w_{i}$ is the inverse of the $i$ th sampling variance, $T_{i}$ is the $i$ th treatment effect estimate, $\bar{T}$ is the weighted estimator of treatment effect; $Q$ is the $\chi^{2}$ heterogeneity statistic and $K$ is the number of trials.

A value greater than $50 \%$ may be considered substantial heterogeneity. If the $\mathrm{I}^{2}$ was found to be significant, a random effects model was used and the sources of heterogeneity of response were investigated by metaregression. Study weights were calculated based on the inverse of the square of the standard error of the effect estimate for each trial (Higgins and Green, 2005).

Forest plots were used to present means and their confidence intervals in a graphic manner. Information presented in forest plots also provided the means and $95 \%$ confidence interval for primary studies. The stan- dard mean difference was calculated by dividing the mean difference in each study with the study's standard deviation to show the difference across studies as an index. The standard mean difference in DMI, milk production, and milk composition between biotin-supplemented and non-supplemented cows was the outcome of interest listed in the forest plots.

Begg's test was conducted to investigate the publication bias (Begg and Mazumdar, 1994). The influence of individual studies on the summary ES was displayed by sensitivity analysis using the metainf command in Stata, generating an influence plot in which summary estimates were computed after sequentially omitting one study at a time (Deeks et al., 2001).

\section{RESULTS}

The summary of effect size estimates of biotin on production in lactating dairy cows derived from metaanalysis is shown in Table 2. Over all of the trials analyzed, after the supplementation of biotin, DMI (ES = $0.386, P=0.012, \mathrm{n}=178)$, milk yield $(\mathrm{ES}=0.421, P$ $=0.002, \mathrm{n}=238)$, fat yield $(\mathrm{ES}=0.280, P=0.041$, $\mathrm{n}=222)$, and protein yield $(\mathrm{ES}=0.440, P=0.001$, $\mathrm{n}=222$ ) increased by $0.87,1.66,0.05$, and $0.05 \mathrm{~kg} / \mathrm{d}$, respectively, whereas little effect was found on the per- 
A.
Source
SMD $(95 \%$ CI $) \quad \%$ Weight

Zimmerly and Weiss (2001)

Majee et al. (2003)

Rosendo et al. (2004)

Ferreira (2006)

Ferreira et al. (2007)

Ferreira et al. (2007)

Ganjkhanlou et al. (2007)

Reynolds et al. (2007)

Enjalbert et al. (2008)

Enjalbert et al. (2008)

Overall (I-squared $=0.0 \%, \mathrm{p}=0.463$ )

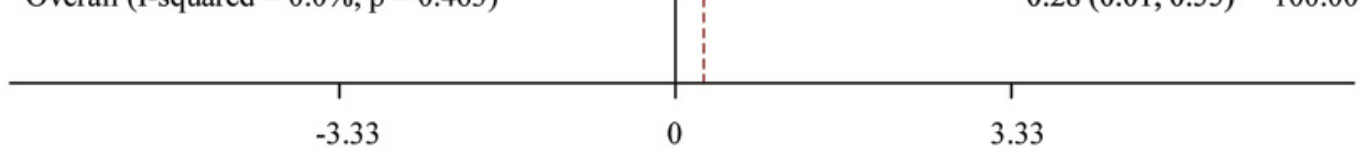

B.

Source

SMD $(95 \%$ CI $) \quad \%$ Weight

Zimmerly and Weiss (2001)

Majee et al. (2003)

Rosendo et al. (2004)

Ferreira (2006)

Ferreira et al. (2007)

Ferreira et al. (2007)

Ganjkhanlou et al. (2007)

Reynolds et al. (2007)

Enjalbert et al. (2008)

Enjalbert et al. (2008)

Yang et al. (2009)

Overall $(\mathrm{I}$-squared $=10.8 \%, P=0.341)$

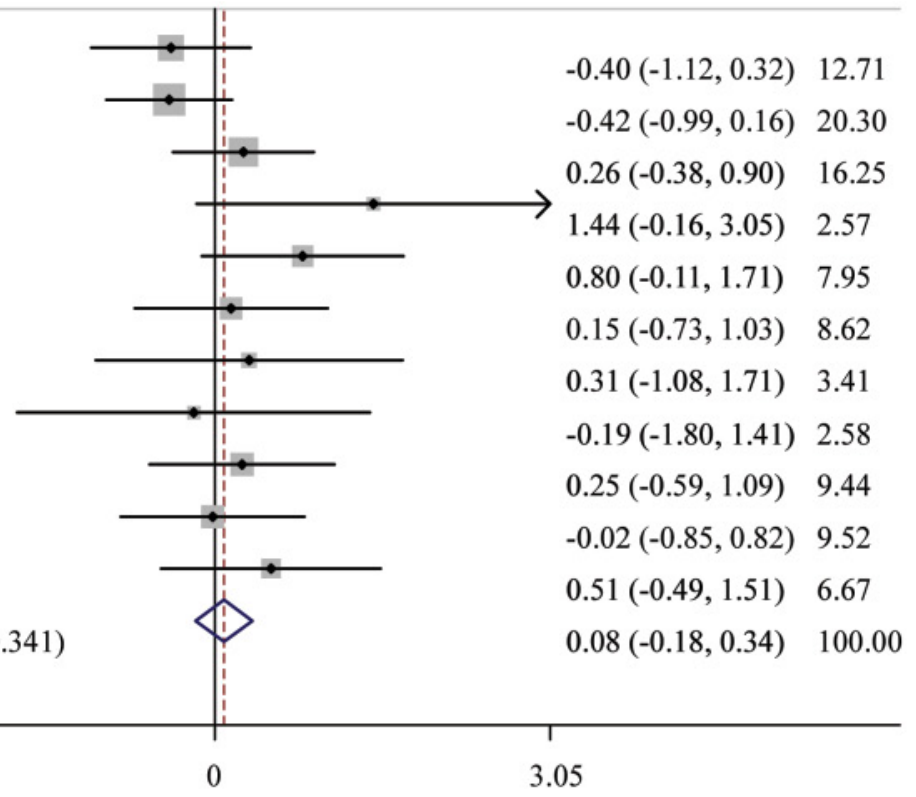

Standardized mean difference

Figure 3. Forest plot of the effect of biotin on milk fat yield (A) and percentage (B) in lactating dairy cows. The x-axis shows the standardized mean difference (SMD, standardized using the z-statistic). The length of the horizontal line represents the $95 \%$ CI for the standardized mean difference of biotin on milk fat yield (A) and milk fat percentage (B) from each study, the size of the square in the center is proportional to the weight assigned to the study, and the specific values are listed in the following row. In (A), the diamond at the bottom on the right of the solid vertical line represents the positive effect of biotin on milk fat yield. In (B), the diamond at the bottom close to the solid vertical line represents the little effect of biotin on milk fat percentage. The overall $\mathrm{I}^{2}$ statistic (a test of heterogeneity) indicated that heterogeneity for the effect of biotin was not significant on milk fat yield $(P=0.463)$ or percentage $(P=0.341)$. Color version available in the online PDF 
A.

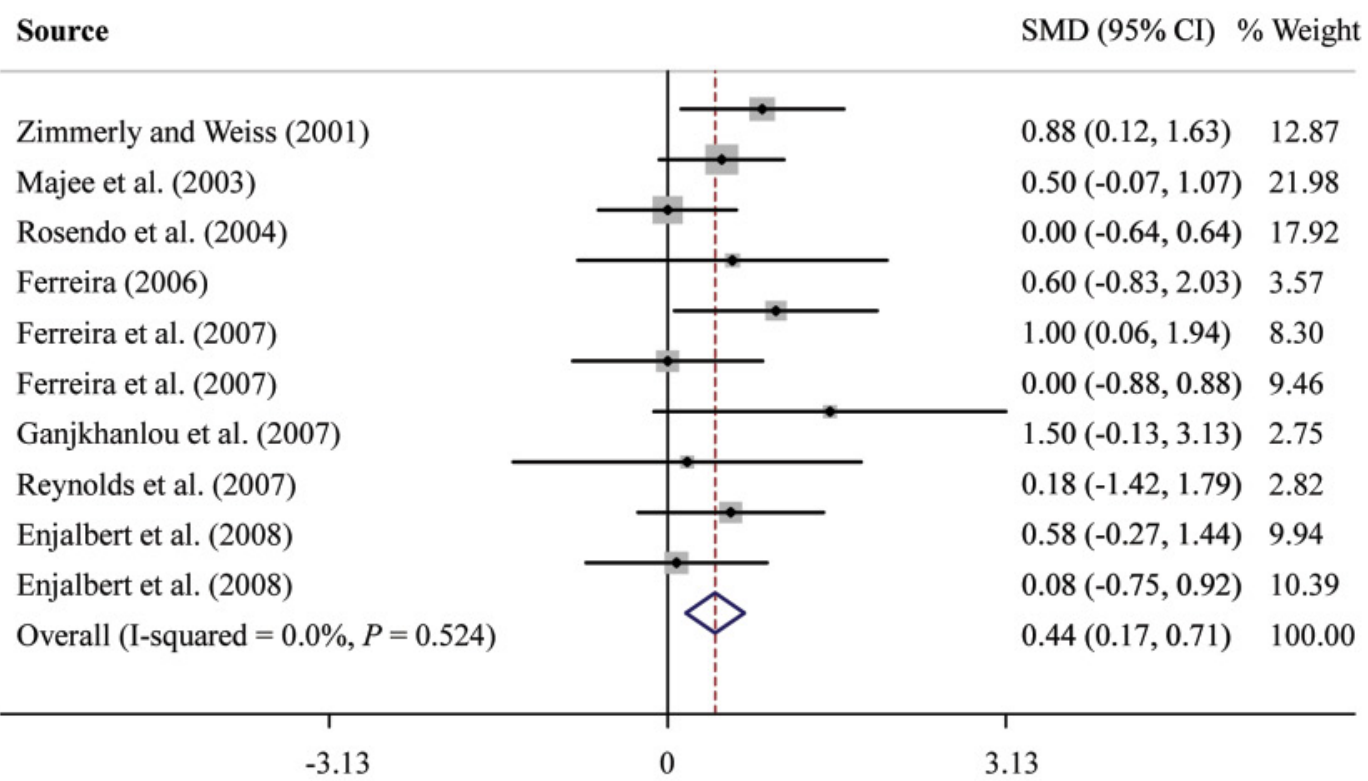

B.

Source

SMD $(95 \% \mathrm{CI}) \quad \%$ Weight

Zimmerly and Weiss (2001)

Majee et al. (2003)

Rosendo et al. (2004)

Ferreira (2006)

Ferreira et al. (2007)

Ferreira et al. (2007)

Ganjkhanlou et al. (2007)

Reynolds et al. (2007)

Enjalbert et al. (2008)

Enjalbert et al. (2008)

Yang et al. (2009)

Overall (I-squared $=1.8 \%, P=0.424)$

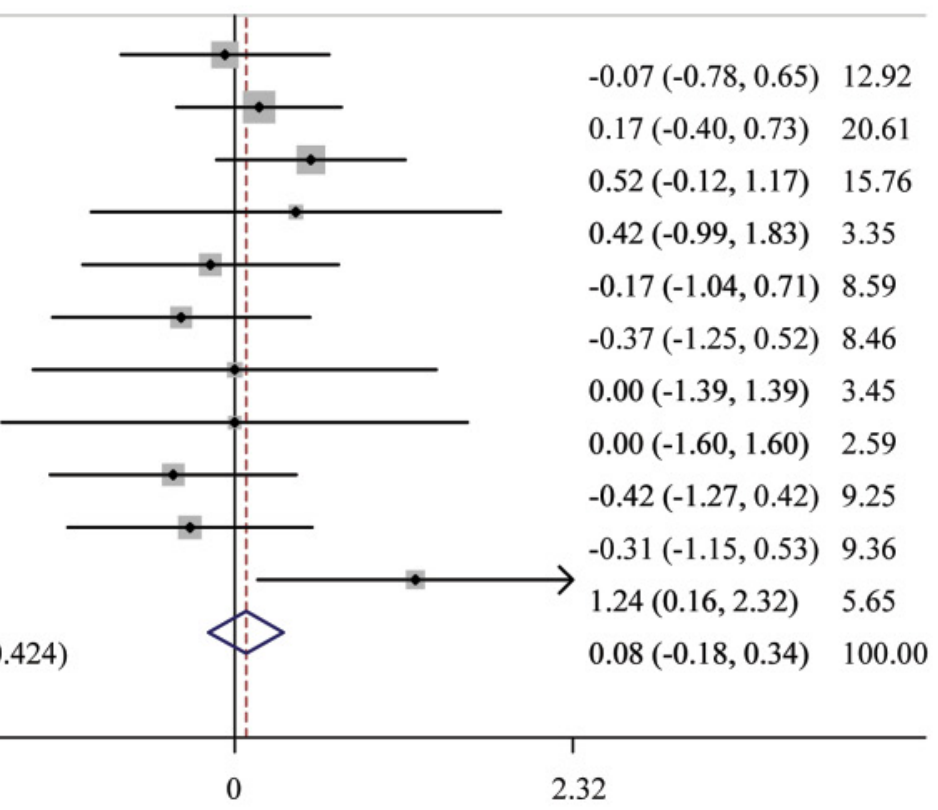

Standardized mean difference

Figure 4. Forest plot of the effect of biotin on milk protein yield (A) and percentage (B) in lactating dairy cows. The x-axis shows the standardized mean difference (SMD, standardized using the z-statistic). The length of the horizontal line represents the $95 \% \mathrm{CI}$ for the standardized mean difference of biotin on milk protein yield (A) and milk protein percentage (B) from each study, the size of the square in the center is proportional to the weight assigned to the study, and the specific values are listed in the following row. In (A), the diamond at the bottom on the right of the solid vertical line represents the positive effect of biotin on milk protein yield. In (B), the diamond at the bottom close to the solid vertical line represents the little effect of biotin on milk protein percentage. The overall $\mathrm{I}^{2}$ statistic (a test of heterogeneity) indicated that heterogeneity for the effect of biotin was not significant on milk protein yield $(P=0.524)$ or percentage $(P=0.424)$. Color version available in the online PDF 
Table 3. Summary of the publication bias of variables

\begin{tabular}{lccc}
\hline & & Coefficient \\
Variable & Coefficient & $95 \%$ CI & $P$-value \\
\hline DMI $(\mathrm{kg} / \mathrm{d})$ & 0.919 & $(-1.266,3.103)$ & 0.343 \\
Milk production $(\mathrm{kg} / \mathrm{d})$ & 1.114 & $(-1.238,3.466)$ & 0.312 \\
Milk fat $(\%)$ & 1.899 & $(-0.615,4.004)$ & 0.072 \\
Milk fat yield $(\mathrm{kg} / \mathrm{d})$ & 1.477 & $(-2.467,2.569)$ & 0.142 \\
Milk protein $(\%)$ & 0.016 & $(-1.369,3.143)$ & 0.988 \\
Milk protein yield $(\mathrm{kg} / \mathrm{d})$ & 0.887 & & 0.391 \\
\hline
\end{tabular}

centage of milk fat $(\mathrm{ES}=0.082, P=0.531, \mathrm{n}=238)$ or milk protein $(\mathrm{ES}=0.079, P=0.546, \mathrm{n}=238)$. The $\mathrm{I}^{2}$ statistic indicated that heterogeneity for all of the variables was not significant (the highest $\mathrm{I}^{2}=12 \%, P=$ 0.328 ; the lowest $\left.\mathrm{I}^{2}=0, P=0.575\right)$. Therefore, it was not necessary to do the meta-regression and the models for all variables were evaluated using a fixed effect.

Figures 1, 2, 3, and 4 present the forest plots of the effect of biotin on milk production, DMI, milk fat yield and percentage, and milk protein yield and percentage, respectively. The overall $\mathrm{I}^{2}$ statistic indicated that heterogeneity for the effects of biotin was not significant on milk production $(P=0.328)$, DMI $(P=0.575)$, milk fat yield $(P=0.463)$ and percentage $(P=0.341)$, and milk protein yield $(P=0.524)$ and percentage $(P$ $=0.424)$.

The result of the Begg's test for publication bias was not significant for all of the variables (Table 3). Figure 5 shows an example of a funnel plot of the effect of biotin on milk production for assessing publication bias. An almost equal number of studies was found on every side of the overall effect size estimate, which meant that no publication bias existed among studies.

Sensitivity analysis revealed no influential studies. The removal of any single study did not change the direction of effect in any analysis, and had little or no change in the overall effect size estimates. An example of influence analysis for milk yield is presented in Fig-

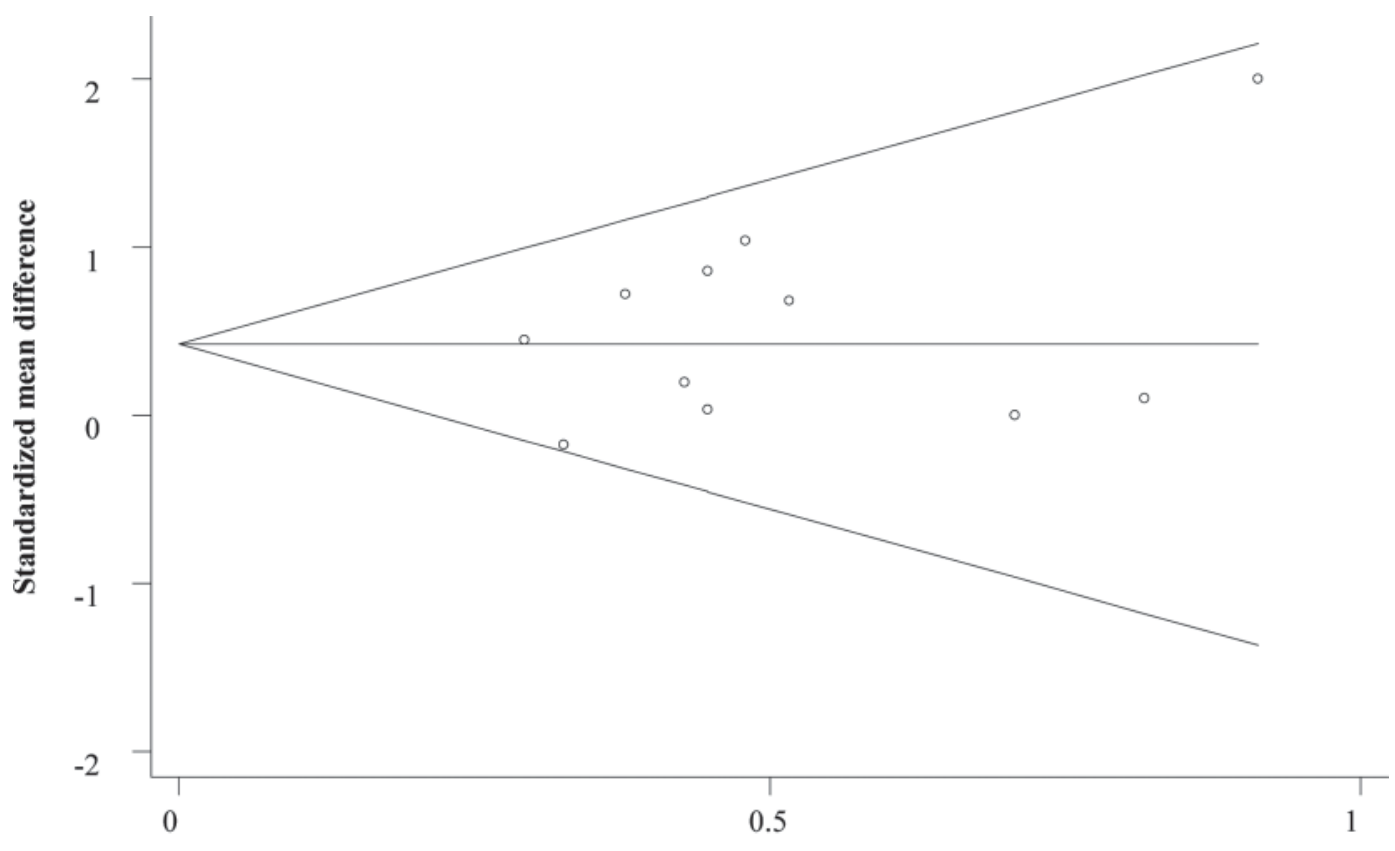

SE of standardized mean difference

Figure 5. Funnel plot of the effect of biotin on milk production for assessing publication bias. The x-axis shows the standard error of the standardized mean difference, and the y-axis shows the standardized mean difference. The horizontal line represents the overall effect size estimate. The 2 diagonal lines indicate an estimate of the $95 \%$ CI of the effect size estimate. An almost equal number of studies was found on every side of the overall effect size estimate, implying no publication bias between studies. 
Zimmerly and Weiss (2001)

Majee et al. (2003)

Rosendo et al. (2004)

Ferreira (2006)

Ferreira et al. (2007)

Ferreira et al. (2007)

Ganjkhanlou et al. (2007)

Reynolds et al. (2007)

Enjalbert et al. (2008)

Enjalbert et al. (2008)

Yang et al. (2009)

Meta-analysis estimates, given named study is omitted

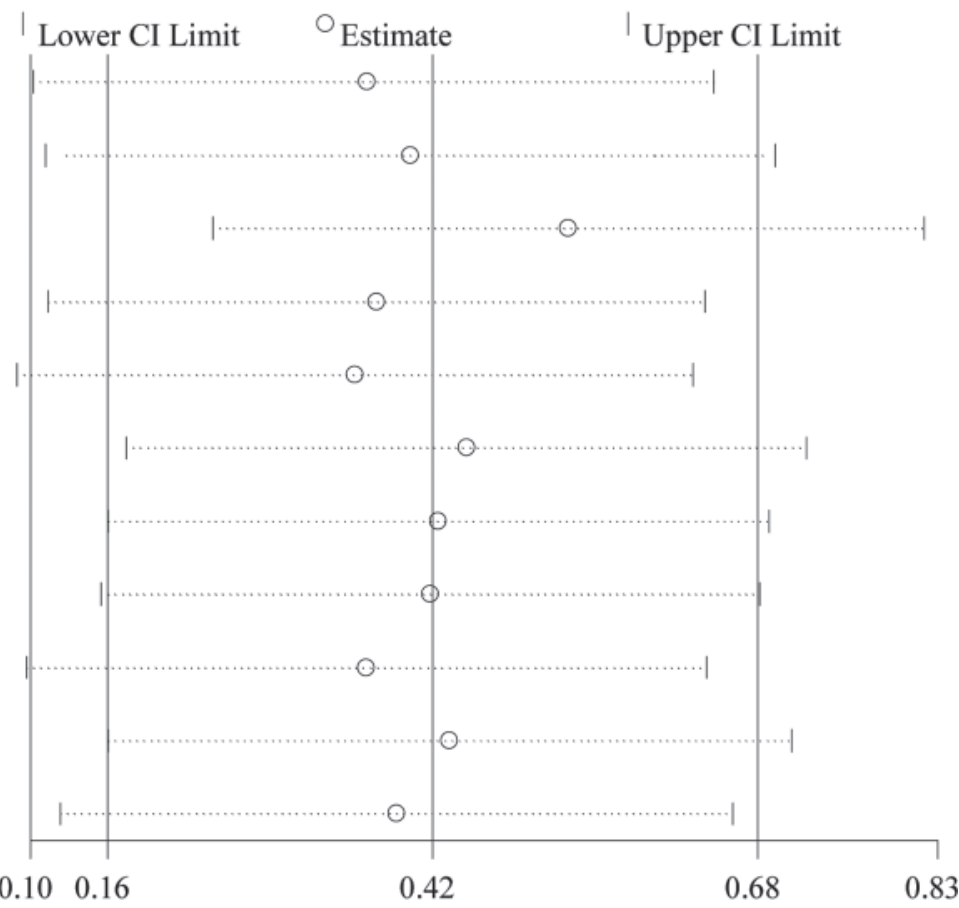

Standardized mean difference

Figure 6. Influence analysis for the effect of biotin on milk production. The x-axis shows the standardized mean difference, and the y-axis is the list of individual studies. The length of the horizontal line and the circle in the line represent the $95 \%$ CI for the overall standard mean difference (SMD) and the value of the SMD by removing the study that is listed on the left, respectively. All circles were located in the $95 \%$ CI for the overall SMD, implying that the conclusion was steady.

ure 6 . The removal of any study did not change the direction or significance of the point estimates.

\section{DISCUSSION}

In the present study, meta-analysis was used to investigate effects of biotin on dairy cattle lactation performance for its extensive and quantitative evaluation. The reliability of this analysis was realized by the adequate statistical power derived from the number of trials, the strict criteria of literature selection and the number of cows evaluated.

The fixed effect model was used to conduct the analysis. St-Pierre (2001) reported that meta-analysis should incorporate the study effect and its interaction effects as random components of a mixed model. However, in this analysis, the heterogeneity among studies was not significant, implying that the study effect is small and the difference of studies has no effect on the final conclusion. Duffield et al. (2008) suggested that only if evidence of heterogeneity $\left(\mathrm{I}^{2}>50 \%\right)$ existed, a random effect model should be used.
Biotin supplementation increased the DMI. The approximate $3.9 \%$ increase in DMI is a consistent response, depending on heterogeneity. The elevated DMI may be accounted for by the improvement of hoof health allowing for more movement. Conversely, lame cows are more likely to lie down and show less desire to eat (Zimmerly and Weiss, 2001). On the other hand, the dairy cattle with improved milk production required more DMI to maintain their nutrition level. The specific reasons are still unknown; therefore, further studies are warranted. For example, cattle with pedometers may be used to detect if movement has increased. Cattle could be housed in tie-stall barns to limit movement in order to investigate whether the DMI was affected by milk production.

Supplemental biotin has shown beneficial effects for milk production compared with the control group (Zimmerly and Weiss, 2001; Majee et al., 2003), whereas Fitzgerald et al. (2000) found that no significant difference in milk yield between treatments with cows in a grass-based system, because such kinds of systems have claw-friendly ground to alleviate hoof disorders. 
Meta-analysis in the current study clearly proved an increase in milk yield through biotin treatments. In addition, low heterogeneity in these responses indicates that the conclusion is credible. Beneficial effects of biotin supplementation on milk production may involve comprehensive factors. Apparently, the increased DMI is accompanied by nutrient intake, which is beneficial for milk production. Moreover, biotin addition can promote the growth of rumen cellulolytic bacteria to improve cellulose digestion for more energy (Fitzgerald et al., 2000). Biotin supplementation increased milk yield in high-producing cows, but not in low-producing cows (Ferreira et al., 2007). The metabolism process in the high-producing dairy cows may be faster than that in the low-production cow. High-producing cows have a faster ruminal turnover and, therefore, more biotin synthesis than do low-producing cows. However, their requirements for biotin would also be higher.

Supplementation of biotin increased the milk fat yield, but not milk fat concentration. The increased fat yield may be related to an increased milk yield with a stable fat percentage. The increased fat yield may also be related to an increase in gluconeogenesis in the liver (Ferreira et al., 2007). Biotin is a cofactor for the gluconeogenic enzyme (Dakshinamurti and Chauhan, 1988) and its supplementation will increase glucose production (Zimmerly and Weiss, 2001). Increased glucose supply to the mammary gland will be oxidized by the pentose phosphate pathway, thereby increasing the availability of reducing equivalents for fatty acid synthesis (Ferreira et al., 2007). The protein yield was increased by $0.05 \mathrm{~kg} / \mathrm{d}$, but milk protein content was not influenced by biotin. In addition to the enhanced milk yield, the increased protein yield may be due to the promotion of biotin to protein synthesis (Dakshinamurti and Chauhan, 1988). Specifically, all of the major cellulolytics in the rumen required biotin for growth (Baldwin and Allison, 1983), and additional biotin would increase microbial protein synthesis, hence beneficial to synthesize protein in milk.

\section{CONCLUSIONS}

The meta-analysis of 9 studies indicated that biotin supplementation of diets of lactating cows resulted in increased DMI, milk yield, milk fat, and protein yield, but had no significant effect on the percentage of milk fat and milk protein.

\section{ACKNOWLEDGMENTS}

Authors gratefully acknowledge H. H. Qing (Zhejiang Provincial Center for Disease Control and Prevention, Hangzhou, China) and T. F. Duffield (Department of
Population Medicine, University of Guelph, Guelph, Canada) for their assistance in statistical analysis, and Michael Herrick (Peking University, Beijing, China) and S. P. Doto (Zhejiang University, Hangzhou, China) for their help in English writing.

\section{REFERENCES}

Abel, H. J., I. Immig, C. Da Costa Gomez, and W. Steinberg. 2001. Effect of increasing dietary concentrate level on microbial biotin metabolism in the artificial rumen simulation system (RUSITEC). Arch. Anim. Nutr. 55:371-376.

Baldwin, R. L., and M. J. Allison. 1983. Rumen metabolism. J. Anim. Sci. 57(Suppl. 2):461-477.

Begg, C. B., and M. Mazumdar. 1994. Operating characteristics of a rank correlation test for publication bias. Biometrics 50:10881101.

Bergsten, C., P. R. Greenough, J. M. Gay, R. C. Dobson, and C. C. Gay. 1999. A controlled field trial of the effects of biotin supplementation on milk production and hoof lesions. J. Dairy Sci. 82(Suppl. 1):34. (Abstr.)

Chen, B., and J. X. Liu. 2010. Dry matter intake as manipulated by dietary cation-anion difference in early lactating dairy cows: A meta-analysis. Chinese J. Anim. Nutr. 22:1-5.

Dakshinamurti, K., and J. Chauhan. 1988. Regulation of biotin enzymes. Annu. Rev. Nutr. 8:211-233.

Deeks, J. J., D. G. Altman, and M. J. Bradburn. 2001. Statistical methods for examining heterogeneity and combining results from several studies in meta-analysis. Pages 285-312 in Systematic Reviews in Health Care: Meta-Analysis in Context. BMJ Publishing Group, London, UK.

Duffield, T. F., A. R. Rabiee, and I. J. Lean. 2008. A meta-analysis of the impact of monensin in lactating dairy cattle. Part 1. Metabolic Effects. J. Dairy Sci. 91:1334-1346.

Egger, M., G. D. Smith, and D. Altman. 2001. Systematic reviews in health care. meta-analysis in context. BMJ Publishing Group, London, UK.

Enjalbert, F., M. C. Nicot, and A. J. Packington. 2008. Effects of peripartum biotin supplementation of dairy cows on milk production and milk composition with emphasis on fatty acids profile. Livest. Sci. 114:287-295

Ferreira, G. 2006. Effect of supplementation on the metabolism of lactating dairy cows. MS Thesis. The Ohio State University, Columbus.

Ferreira, G., W. P. Weiss, and L. B. Willett. 2007. Changes in measures of biotin status do not reflect milk yield responses when dairy cows are fed supplemental biotin. J. Dairy Sci. 90:1452-1459.

Fitzgerald, T., B. W. Norton, R. Elliott, H. Podlich, and O. L. Svendsen. 2000. The influence of long-term supplementation with biotin on the prevention of lameness in pasture fed dairy cows. J. Dairy Sci. 83:338-344.

Fritsche, A., G. A. Mathis, and F. R. Althaus. 1991. Pharmacological effects of biotin on epidermal cells. Schweiz. Arch. Tierheilkd. $133: 277-283$.

Ganjkhanlou, M., M. Salimi, A. Nikkhah, and A. Zali. 2007. Effects of supplemental dietary biotin on performance of Holstein dairy cows. Pak. J. Biol. Sci. 10:2960-2963.

Higgins, J. P. T., and S. Green. 2005. Cochrane Handbook for Systematic Reviews of Interventions 4.2.5. In The Cochrane Library, Issue 3, 2005. John Wiley \& Sons Ltd., Chichester, UK.

Higgins, J. P. T., S. G. Thompson, J. J. Deeks, and D. G. Altman. 2003. Measuring inconsistencies in meta-analyses. BMJ 327:557560

Lischer, C. J., A. Hunkeler, H. Geyer, and P. Ossent. 1996. The effect of biotin in the treatment of uncomplicated claw lesions with exposed corium in dairy cows. Part II: The healing process in supplemented animals. Page 31 in Proc. 9th Int. Symp. Disorders Ruminant Digit Int. Conf. Lameness Cattle. Koret School of Veterinary Medicine, Rehovot, Israel. 
Majee, D. N., E. C. Schwab, S. J. Bertics, W. M. Seymour, and R. D. Shaver. 2003. Lactation performance by dairy cows fed supplemental biotin and a B-vitamin blend. J. Dairy Sci. 86:2106-2112.

Margerison, J. K., B. Winkler, and B. Penny. 2002. The effect of supplementary biotin on milk production in Holstein cows. Page 219 in Proc. XXII World Buiatrics Congress, Hannover, Germany.

Midla, L. T., K. H. Hoblet, W. P. Weiss, and M. L. Moeschberger 1998. Supplemental dietary biotin for prevention of lesions associated with aseptic subclinical laminitis (pododermatitis aseptic diffusa) in primiparous cows. Am. J. Vet. Res. 59:733-738.

NRC. 2001. Nutrient Requirements of Dairy Cattle. 7th rev. ed. Natl. Acad. Sci., Washington, DC.

Reynolds, C. K., D. E. Beever, W. Steinberg, and A. J. Packington. 2007. Net nutrient absorption and liver metabolism in lactating dairy cows fed supplemental dietary biotin. Animal 1:375-380

Rosendo, O., C. R. Staples, L. R. McDowell, R. McMahon, L. Badinga, F. G. Martin, J. F. Shearer, W. M. Seymour, and N. S.
Wilkinson. 2004. Effects of biotin supplementation on peripartum performance and metabolites of Holstein cows. J. Dairy Sci. $87: 2535-2545$

Schwab, E. C., and R. D. Shaver. 2005. B-vitamin nutrition for dairy cattle. Pages 1-10 in Penn State Dairy Cattle Nutrition Workshop Grantville.

St-Pierre, N. R. 2001. Invited review: Integrating quantitative findings from multiple studies using mixed model methodology. J. Dairy Sci. 84:741-755.

Whitehead, A. 2002. Meta-Analysis of Controlled Clinical Trials. John Wiley \& Sons, Chichester, UK.

Yang, K., Y. X. Gao, Y. F. Cao, and J. G. Li. 2009. Effects of dietary biotin supplement on performance and blood biochemical parameters in lactating cows. Chinese J. Anim. Nutr. 21:853-858.

Zimmerly, C. A., and W. P. Weiss. 2001. Effects of supplemental dietary biotin on performance of Holstein cows during early lactation. J. Dairy Sci. 84:498-506. 